\title{
4C/ID in medical education: How to design an educational program based on whole-task learning: AMEE Guide No. 93
}

Citation for published version (APA):

Vandewaetere, M., Manhaeve, D., Aertgeerts, B., Clarebout, G., Van Merrienboer, J. J. G., \& Roex, A. (2015). 4C/ID in medical education: How to design an educational program based on whole-task learning: AMEE Guide No. 93. Medical Teacher, 37(1), 4-20. https://doi.org/10.3109/0142159X.2014.928407

Document status and date:

Published: 01/01/2015

DOI:

10.3109/0142159X.2014.928407

Document Version:

Publisher's PDF, also known as Version of record

Document license:

Taverne

Please check the document version of this publication:

- A submitted manuscript is the version of the article upon submission and before peer-review. There can be important differences between the submitted version and the official published version of record.

People interested in the research are advised to contact the author for the final version of the publication, or visit the DOI to the publisher's website.

- The final author version and the galley proof are versions of the publication after peer review.

- The final published version features the final layout of the paper including the volume, issue and page numbers.

Link to publication

\footnotetext{
General rights rights.

- You may freely distribute the URL identifying the publication in the public portal. please follow below link for the End User Agreement:

www.umlib.nl/taverne-license

Take down policy

If you believe that this document breaches copyright please contact us at:

repository@maastrichtuniversity.nl

providing details and we will investigate your claim.
}

Copyright and moral rights for the publications made accessible in the public portal are retained by the authors and/or other copyright owners and it is a condition of accessing publications that users recognise and abide by the legal requirements associated with these

- Users may download and print one copy of any publication from the public portal for the purpose of private study or research.

- You may not further distribute the material or use it for any profit-making activity or commercial gain

If the publication is distributed under the terms of Article $25 \mathrm{fa}$ of the Dutch Copyright Act, indicated by the "Taverne" license above, 


\section{C/ID in medical education: How to design an educational program based on whole-task learning: AMEE Guide No. 93}

\section{Mieke Vandewaetere, Dominique Manhaeve, Bert Aertgeerts, Geraldine} Clarebout, Jeroen J. G. Van Merriënboer \& Ann Roex

To cite this article: Mieke Vandewaetere, Dominique Manhaeve, Bert Aertgeerts, Geraldine Clarebout, Jeroen J. G. Van Merriënboer \& Ann Roex (2015) 4C/ID in medical education: How to design an educational program based on whole-task learning: AMEE Guide No. 93, Medical Teacher, 37:1, 4-20, DOI: 10.3109/0142159X.2014.928407

To link to this article: https://doi.org/10.3109/0142159X.2014.928407

View supplementary material $\asymp$

曲 Published online: 23 Jul 2014.

Submit your article to this journal $\asymp$

ЏIII Article views: 3918

Q View related articles $\sqsubset$

View Crossmark data $₫$

Citing articles: 27 View citing articles 지 


\title{
4C/ID in medical education: How to design an educational program based on whole-task learning: AMEE Guide No. 93
}

\author{
MIEKE VANDEWAETERE ${ }^{1}$, DOMINIQUE MANHAEVE ${ }^{1}$, BERT AERTGEERTS ${ }^{1}$, GERALDINE CLAREBOUT ${ }^{1}$ \\ JEROEN J. G. VAN MERRIËNBOER ${ }^{2} \&$ ANN ROEX $^{1}$ \\ ${ }^{1}$ University of Leuven, Belgium, ${ }^{2}$ Maastricht University, the Netherlands
}

\begin{abstract}
Medical education increasingly stresses that medical students should be prepared to take up multiple roles as a health professional. This requires the integrated acquisition of multiple competences such as clinical reasoning and decision making, communication skills and management skills. To promote such complex learning, instructional design has focused on the use of authentic, real-life learning tasks that students perform in a real or simulated task environment. The four-component instructional design model (4C/ ID) model is an instructional design model that starts from the use of such tasks and provides students with a variety of learning tools facilitating the integrated acquisition of knowledge, skills and attitudes. In what follows, we guide the reader on how to implement educational programs based on the 4C/ID model and illustrate this with an example from general practice education. The developed learning environment is in line with the whole-task approach, where a learning domain is considered as a coherent, integrated whole and where teaching progresses from offering relatively simple, but meaningful, authentic whole tasks to more complex tasks. We describe the steps that were taken, from prototype over development to implementation, to build five learning modules (patient with diabetes; the young child with fever; axial skeleton; care for the elderly and physically undefined symptoms) that all focus on the integrated acquisition of the Canadian Medical Education Directives for Specialists roles in general practice. Furthermore, a change cycle for educational innovation is described that encompasses practice-based challenges and pitfalls about the collaboration between different stakeholders (students, developers and teachers) and the transition from traditional, fragmented and classroom-based learning to integrated and blended learning based on sound instructional design principles.
\end{abstract}

\section{Introduction}

There is a general agreement that medical curricula should be outcome- and competency-based (Fernandez et al. 2012). This implies that the primary goal of modern medical education is to train students to become competent physicians (competency-based medical education or CBME). Inspired by this idea, many fruitful attempts have been made on how to define medical competence. Using national training frameworks such as Canadian Medical Education Directives for Specialists (CanMEDS; Frank \& Danoff 2007), Accreditation Council for Graduate Medical Education (Swing 2007) and the Dundee Outcomes (Davis 2003), curricula in medical education can be organized according to competency-linked outcome expectations and standards that should be met by the learners. Because the CanMEDS framework is used as the backbone for the medical education curriculum at the University of Leuven in Belgium, this framework was also used for the development of the learning environment described in this Guide.

The CanMEDS 2005 Physician Competency Framework (Frank 2005) is an internationally used definition that describes how physicians should integrate their roles (as medical expert,

\section{Practice points}

- Innovation in medical education is a cyclical process of change and stepwise improvement.

- Whole-task learning in medical education requires strong collaboration between developers and endusers.

- End-users of medical innovation are both students and teachers as well.

- The 4C/ID model is an instructional design model that guides the design of whole-task based learning environments.

- By following 10 concrete steps, medical courses and curricula can be transformed into powerful wholetask-based learning environments.

communicator, collaborator, academic, organizer, health promoter and professional) in order to apply their knowledge, skills and professional attitudes to provide patient-centered care. In practice, the roles as described in the CanMEDS framework have to be integrated into a seamless whole,

Correspondence: Dr. Mieke Vandewaetere, KU Leuven @ Kulak, E. Sabbelaan 53, 8500 Kortrijk, Belgium. Tel: 003256246094 ; E-mail: mieke.vandewaetere@kuleuven-kulak.be

This article has been republished with minor changes. These changes do not impact the academic content of the article. 
Complex learning refers to the integrated acquisition of knowledge, skills and attitudes and to the coordination of qualitatively different constituent skills. Moreover, complex learning also involves the transfer of what is learned in school and training settings to daily life or professional settings (van Merriënboer \& Kirschner 2013).

reflecting the daily activities of the physician. Hence, for a physician's (in this case, a general practitioner) successful performance in daily practice, it is not sufficient just to have the knowledge about and insight in, for example, diabetes. Physicians should also be able to translate this knowledge into appropriate care policies for the patient, to communicate with the patient and to organize practice in such a way that healthcare goals are achieved. This integration of knowledge, skills and attitudes is crucial to a successful completion of a physician's task performance.

Consequently, the CanMEDS framework and its specific implementations imply that medical education may benefit from instruction and learning environments that foster the integrated acquisition of knowledge, skills and attitudes. Frank (2005) and van Herwaarden et al. (2009) argue that focusing on the real, authentic tasks that health professionals need to deal with will support such integrated learning. By doing so, they refer to what is called complex learning or whole-task learning (Box 1).

\section{Whole-task learning in medical education}

There are two compelling reasons for using the approach of complex or whole-task learning in medical education.

First, whole-task models provide a solid framework for the development of learning activities that foster students' functioning in variable and complex settings (Yardley et al. 2013). As a result of using a whole-task approach, the development of a rich set of mental models and cognitive strategies is facilitated, allowing students to use efficient problem solving strategies in various health care situations. By using real-life authentic tasks, complex learning is supported and hence the transfer from the curriculum to the workplace becomes more feasible (Mayer 2010; van Merriënboer \& Sweller 2010).

Second, models of whole task learning may meet the call for a more explicit use of evidence-based principles in the practice of medical education (Gibbs et al. 2011). Although there is a general agreement on the key aspects of competency-based curricula, its practical implementation has had little scientific underpinning. Instructional design models can be used to guide medical curricula toward whole-task learning. The four-component instructional design model (4C/IDmodel; Box 2) (van Merriënboer \& Kirschner 2007, 2013; van Merriënboer \& Sweller 2010) is an evidence-based instructional design model that supports the design and development process of whole-task learning environments. It does so by providing concrete guidelines and usable designs (Hoogveld et al. 2011). This model has already been applied in several
The four-component instructional design (4C/ID) model applies a holistic approach to learning and instruction, hereby dealing with the complexity of real-life tasks without losing sight of the separate elements and the relationships between those elements (van Merriënboer 1997). This approach deals with persistent problems like: compartmentalization; separation of a whole competence in distinct parts or categories like declarative knowledge, procedural knowledge and attitudes; fragmentation, breaking complex skills or competencies in smaller parts without taking into account the interactions between the parts; and the transfer paradox, when students learn complex tasks in an isolated manner, it will be more difficult for them to transfer what they have learned to the reality of the work settings because what works well for reaching isolated, specific objectives often does not work when it comes to reaching integrated objectives.

domains for the acquisition of complex skills like business conversation skills (Vandercruysse et al. 2013), physiotherapy (Gerards-Last \& Geraets 2011) and vocational education in nursing care (Fastré et al. 2010).

The aim of this AMEE Guide is to provide the reader with a stepwise instruction on how to implement educational programs based on the 4C/ID model in a medical curriculum. In this guide, the focus is on the development of a course for general practice students; however, the principles are transferable to other courses. The course is blended, providing a blend of face-to-face instruction, computer-based instruction and workplace learning. This is reflected by the computerbased individual or group tasks, the classes and the alignment of tasks and classes with internship weeks.

\section{The 4C/ID model: From theory to practice}

As indicated in its name, the model comprises four major components, all interrelated and each component uniquely contributing to the development of complex skills (see Figure 1). The four components that are identified are as follows: (1) learning tasks; (2) supportive information (the theory); (3) procedural information (the how to's) and (4) parttask practice (focused repetitive practice or "drill").

In Figure 1, the learning tasks are indicated by the circles. They provide the backbone of the educational program. Learning tasks that are performed in the workplace are called training tasks. Often, learners will receive support and guidance when they are working on the learning tasks; this is indicated by the filling of the circles. Support and guidance will typically decrease as learners acquire more expertise. Moreover, learners will often be asked to reflect on the quality of their task performance, which is indicated by the diamonds connected to the large circles. The supportive information is indicated by the L-shaped figure. This information helps learners to perform non-routine aspects of learning tasks, that is, aspects that require problem solving, reasoning and decision making. The procedural information or just-in-time information is indicated by the rectangle with upward pointing arrows. This information is offered at the task-level and informs learners on how to perform "recurrent" aspects of learning tasks, that is, aspects to be performed as routines after 


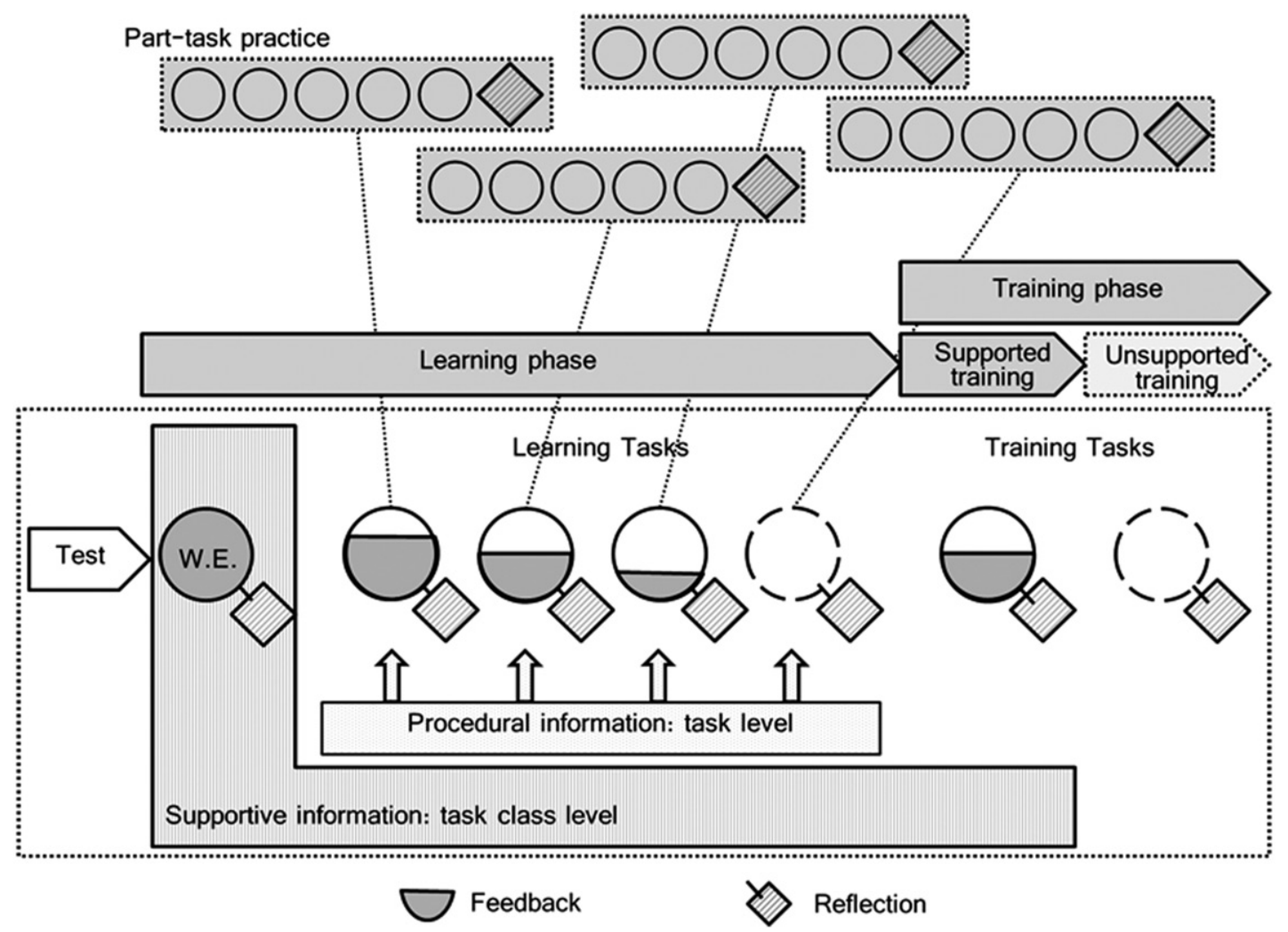

Figure 1. General practice 4C/ID model with the four main components.

the educational program has been completed. The last component is the part-task practice, indicated by the small circles grouped in a rectangle. Part-task practice involves a lot of repetitive practice and is provided when a very high level of automaticity is required for a particular recurrent aspect of the task. Furthermore, part-task practice can be accompanied by a reflection task at the end of the practice series (indicated by a diamond). The aim is to strengthen schema automation, and hence it typically involves extended repetitive practice. A last element that is represented in Figure 1 is the test (indicated by the right-pointing arrow). More than assessing a students' already available relevant knowledge, this test informs students about the performance standards and introduces them to the topic and complexity of the learning tasks.

In order to transfer and organize learning materials into the framework of the 4C/ID model, identifying the four components is only one part of the design process. There are additional, auxiliary activities that support the good design of a 4C/ID-based learning environment. Together, these activities are described as the 10 steps (to whole-task course development) or the 10 activities that make up the design process (van Merriënboer \& Kirschner 2013). The work of van Merriënboer and Kirschner (2013) provides essential information and a more detailed elaboration on each of the 10 steps described below.

In order to help the reader keep a coherent overview, these steps will be discussed in four sections, one for each respective component. Within each section, the reader will get some theoretical underpinning, as well as the relevant steps and illustrations using the General Practice 4C/ID course at the University of Leuven (KU Leuven).
In parallel with taking the 10 steps for the development of the content of the course, it is recommended to draw a plan for the implementation of the course. The latter involves conceptual issues (software, design and structure of the learning environment), change management as well as the design of a system for quality control (how to manage and improve the quality of the course). These issues will be elaborated in the Discussion section of this Guide.

\section{Ten steps to develop the content of the whole-task based medical course}

Component 1: Learning tasks

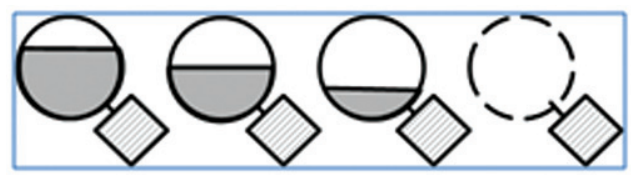

The first component (indicated with large circles in Figure 1) comprises a sequence of learning tasks (van Merriënboer \& van der Vleuten 2012), which more or less mirrors the physician's professional tasks. They can be concretized in three steps.

\section{Step 1: Design learning tasks}

The learning tasks are chosen in such a way that they are representative for the physicians work. They are so-called "whole tasks" or complex problems. In order to contribute to a 
higher transfer of learning, the tasks vary from one another as they would in a real-life situation. For example, when learning to assess the diabetic patient's foot, tasks can focus on simple and complex situations; assessing the foot without or with neuropathy or ulcers; having little or much information about a patient's health condition, and so forth. This "variability of practice" greatly contributes to the transfer of knowledge, skills and attitudes to other, non-familiar situations (Norman 2009). Most learning tasks include both routine and nonroutine aspects. Routine aspects are, for example, asking a sequence of questions during history taking or a clinical examination of the diabetic's foot; they are also called "recurrent" aspects, in order to indicate that they will be performed as routine after students have completed the educational program. Non-routine aspects are actions that are rather new to students, require effort and have a problemspecific outcome; they are also called "non-recurrent" aspects to indicate that they still require problem solving, reasoning or conscious decision making after students have finished the educational program. For example, combining information from various sources (history taking, clinical examination and blood test results) is a non-recurrent skill that requires the combination of cognitive schemata in order to engage in problem-solving behavior and the application of cognitive strategies (van Merriënboer et al. 2002).

Besides varying in their content and presentation, tasks may also vary in their instruction. Moreover, there is a decrease in support and guidance as the student proceeds through the program (see the filling of the circles in Figure 1) and for particular tasks, students are invited to reflect after task completion (see striped diamonds in Figure 1). This leads to several exercise or task types that can be offered in the educational program, such as a mini-case diagnosis, patient stories, commenting on a scientific article, development of an information leaflet for patients, presenting work to colleagues, role play, discussion with patient, colleague or other healthcare professionals; reflection; peer feedback; expert assessment; spot diagnosis; filter case; reasoning case; and so forth. All types of learning tasks with indications on how they can be offered are listed in Appendix A, available as Supplemental Material at http://informahealthcare.com/jour$\mathrm{nal} / \mathrm{mte}$.

Another variation in learning tasks is the distinction between tasks that can be completed during the course and workplace-based learning tasks. The latter are tasks that can be done during the internship of students, often in collaboration with medical experts who supervise the student. Examples of such tasks are as follows: observing and reflecting on history taking; participating in a multidisciplinary team meeting, writing prescriptions and asking feedback from the physician or internship trainer.

\section{Step 2: Develop assessment instruments}

As in any other competency-based curriculum, assessment instruments are crucial elements in the process of complex learning. They assess whether predefined standards have been met and to provide learners with feedback as to improve and guide their learning process. In the 4C/ID model, the main objective is the successful completion of a set of "whole tasks", which requires the integration and coordination of knowledge, constituent skills and attitudes. To ensure that all constituent skills are represented in the assessment instruments, one could develop an assessment matrix representing whole tasks, (constituent) skills and interrelations between those skills. Subsequently, the skills can be linked with performance objectives that clearly describe what learners will be able to do after they finished the program. Parts of the objectives are standards for acceptable performance. These standards include relevant criteria (e.g. without error and within 10 minutes), values (e.g. taking into account the recent guidelines for diabetes management and in accordance with the electronic health record) and attitudes (e.g. giving relevant arguments for treatment and using active listening techniques in a conversation). Performance standards are needed to distinguish acceptable from unacceptable performance and make it possible to inform students (and teachers) about the actual performance and the desired outcomes.

To inform students about the performance standards, one could offer a self-assessment quiz at the beginning of a learning module. On the one hand, this test activates a students' prior knowledge (Merrill 2002); while on the other hand, students become familiar with the standards by which their performance will be evaluated. Doing so, a student can choose to remediate before starting the learning module or to, during task completion, focus more on the content that is not fully mastered yet.

One way to inform students about the performance standards linked to the desired professional behavior (to what standards will their performance be compared?) is to use worked examples. A worked example can take the form of a video of a consultation, a step-by-step approach for taking a motivational interview from a patient, a knowledge test where the student is guided toward the most appropriate or correct answer by offering (parts of) a model solution and so forth. Central in a worked example is that it reflects the "golden standard", the expert behavior. As such, a worked example task becomes a modeling task where not only the solution is offered but also the process to come to the solution. This helps students to recognize the standards for acceptable performance and to act accordingly to reach the outcomes. However, we cannot assume that all students are able to recognize the underlying standards, or that they can distinguish what is crucial in the expert's behavior and what is not. Therefore, students can be asked to evaluate the performance of the expert according to the standards for acceptable performance by which they will be evaluated during or after task completion (Gulikers et al. 2008, Fastré et al. 2010). By doing so, performance objectives and standards are introduced to students in a real context. A worked example ideally stays available as part of the supportive information (indicated by the lowest bar in Figure 1; WE stands for worked example). Students are thus able to consult the worked example and its accompanying standards on a self-directed basis.

In line with promoting self-directed learning, two types of assessments can be applied in the setting of medical education (van Merriënboer \& van der Vleuten 2012): (1) supported assessment in which students are assessed while all 
Table 1. Relevant principles and auxiliary steps for the development of component 1: Learning tasks.

Component 1: Learning tasks
Principles
- Real-life, whole-task practice
- Organized in task classes
- Simple-to-complex sequencing of task classes
- Equivalent, within a task class, with respect to complexity and required knowledge
- High variability of practice within each task class
$\begin{array}{r}\text { Scaffolding: Decrease of support and guidance per task within one task class } \\ \text { 1. Design learning tasks } \\ \text { Set of typical learning tasks that represent the whole complex skill } \\ \text { Represents what the training program aims to achieve } \\ \text { Articulation of to-be-reached standards } \\ \text { In order to inform learners about the quality of their performance and to determine whether } \\ \text { standards have been met } \\ \text { Order tasks in such a way that the learning process is optimized - by increasing } \\ \text { complexity and, at each level of complexity, by decreasing support and guidance }\end{array}$

supporting materials are available and can be consulted in the learning environment and (2) unsupported assessment in which support is no longer available in the learning environment and students have to seek information on a self-directed basis as in regular medical practice. By offering both types of assessment in the learning tasks, reflective practice is promoted. If necessary, students are instructed with part-task practice to foster automation of smaller parts of the task (e.g. practicing motivational communication skills) to deepen the understanding of parts of the task (e.g. how to distinguish the different phases in a motivational conversation with the patient) in order to improve their overall task performance. Furthermore, immediate feedback is provided as well as the opportunity to repeatedly perform the part-task practice and smaller parts of the task. By doing so, students are supported in the development of their self-assessment and self-regulation strategies in order to reach expert performance. Expert performance only continues to improve as a function of more experience and deliberate practice (Ericsson 2004).

\section{Step 3: Sequence learning tasks}

As described above, a sequence of varying tasks forms the backbone of the learning environment. This facilitates the integration of knowledge, skills and attitudes, hence the acquisition of competences (van Merriënboer \& van der Vleuten 2012). Therewith, the 4C/ID model foresees to group learning tasks that have a similar complexity level and similar required knowledge in so-called task classes. Throughout the training program, learners will be guided from easy and simpler task classes to increasingly more difficult and complex task classes. In other words, learners will need increasing amounts of integrated knowledge as they go from one task class or level of complexity to the next one.

Task classes differ from each other in that they comprise tasks of a different complexity level requesting different knowledge or more elaborated knowledge for their successful performance. However, although tasks within one task class are similar with respect to complexity, they may differ from each other on many other aspects. Ensuring task variability within a task class, i.e. taking into consideration many real world contexts that may be encountered by experts in the subject matter domain, should enable learners to develop rich cognitive schemata, which allow for schema-based transfer of learning (Paas \& van Merriënboer 1994). Tasks within a task class should therefore show variability of practice and, as will be discussed in the sections that describe component 2 (supportive information) and component 3 (procedural information), differ in the amount of support or guidance that is associated with the tasks. Within a task class, there is a decrease in the support offered to the learner: the first task is accompanied by maximal support, while the last task has no or minimal additional support (indicated by the filling of the circles in Figure 1). In the subsequent task class, then again, the first task is accompanied by maximal support. This process of providing support and guidance that is in accordance with the progress of the learner is also called (first-order) scaffolding (van Merriënboer et al. 2002).

Once the learning tasks and assessment instruments are developed and sequenced (summary see Table 1), further steps focus on the identification and development of information that supports the learning process. Steps 4-7 entail the design and development of supportive information and are discussed in the next section.

Table 1 summarizes the relevant principles for the development of learning tasks and lists the three steps that designers can take in order to develop a series of complex, authentic and whole tasks.

\section{Illustration}

Learning modules. Within this Guide, the modules "Patient with diabetes" and "The young child with fever", both developed at the KU Leuven General Practice Department, are used to illustrate how one can develop and structure a $4 \mathrm{C} /$ ID-based learning environment. 
Ingeschakeld: Statistiekentracering

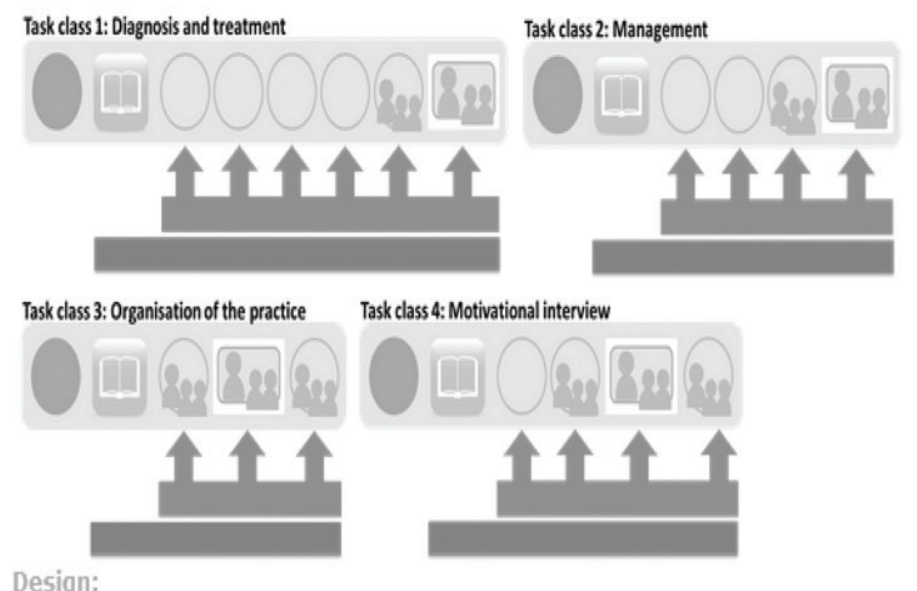

Every task class starts with an example from practice, followed by a self-test. The test will provide an indication of your already available relevant knowledge. After the test, you complete a series of tasks. Before some tasks, we will ask you to read some literature in advance (green bar). While you complete the tasks, other supporting information can be offered (for example: treatment protocols, indicated by the blue bar). All the provided information is also available in the library.

After finishing this learning module, you will be able to ...

- successfully complete a consultation with a patient with diabetes. You do so by taking a focused history and clinical examination, by diagnosing diabetes, by using the electronic health record (ERH) to propose an adjusted management plan and follow-up and by motivating the patient for life style changes.

- organise your practice in such a way that it results in better diabetes care. You can do so by, based upon the current guidelines and by using the ERH, performing audits and following these, to design a plan for better diagnosis and management of patients with diabetes.

Timing: Please complete task classes 1 and 2 as preparation for the lecture on Diabetes.

Please complete task class 3 as preparation for the lecture on Electronic Health Record (ERH).

Who to contact in case of questions: Medical teacher 1 (for questions regarding diabetes) - Medical teacher 2 (for questions regarding EHR and practice management) - Medical teacher 3 (for questions regarding communication).

Figure 2. The learning module "Patient with diabetes" with four task classes.

Task classes. When students enter the learning module, they not only receive an overview of the structure of the module (task classes) and the amount of tasks but they are also informed about the performance objectives per task class (i.e. what they will be able to do after finishing the task class), the timing and deadlines and who to contact in case of questions about the content.

In the learning module "Patient with diabetes", the tasks are ordered in four task classes, all presented graphically in Figure 2 showing the main screen of the learning module. Each task class focuses additionally on one of the CanMEDS roles and is more complex than a previous task class. The first task class of the learning module comprises tasks and case studies focusing on the declarative knowledge about diabetes (like diagnosis and treatment). The second task class also provides tasks on diagnosis and treatment but shifts the focus of the exercises to management of patients with diabetes, hence stressing the role of the doctor as a collaborator and professional. The third task class then provides tasks emphasizing the role of manager, while the fourth (and last) task class stresses the communicator's role. By adding foci (which each imply the acquisition of more domain knowledge) from one task class to the other, the complexity gradually increases.
Tasks. Several tasks are offered in the learning environment. Table 2 provides the icons for different types of tasks.

Each task class is represented by a series of icons, indicating how many tasks and what tasks are offered in the task class. For example, the first task class, Diagnosis and Treatment, consists of eight tasks, as presented in Figure 3.

The first task (the large circle, see Figure 3, part A) for students to complete is a worked example, in this case, a problem-based knowledge test. By answering the questions on this test, students obtain information about their knowledge, receive feedback on their answers and are provided with the expert's answer to the question and the reasoning process to come to the answer. Furthermore, they are introduced to the content of the task class and what the standards are for acceptable performance. Hence, students are informed about what knowledge, skills and attitudes they are expected to demonstrate after completing the task class (i.e. the performance objectives).

The second task (the square with the book icon, see Figure 3, part B) represents the supportive information for the whole task class. Students are instructed to read the materials as to complete this task. These are provided by documents and web links focusing on theoretical overviews and 


Individual computer-based task
E.g. using a computerized test with individualized feedback, students practice the application of guidelines
in the treatment of diabetes (all questions are case-based and include questions on communication skills,
practice management, etc.)
Individual computer-based task to prepare for class(es)
E.g. using a short video introducing the mock patient and access to his electronic health record, the
student has to propose an appropriate management plan. During the lecture, students will do role plays to
practice how to explain this to the patient.
Learning group activity
E.g. students have to reflect upon the indications of bariatric surgery for non-compliant obese patients.
Training - workplace learning task
E.g. Students have to perform a consultation with a real diabetic patient and record this on video.
The video is discussed with the GP trainer.
Optional task

\section{Task class 1: Diagnosis and treatment}

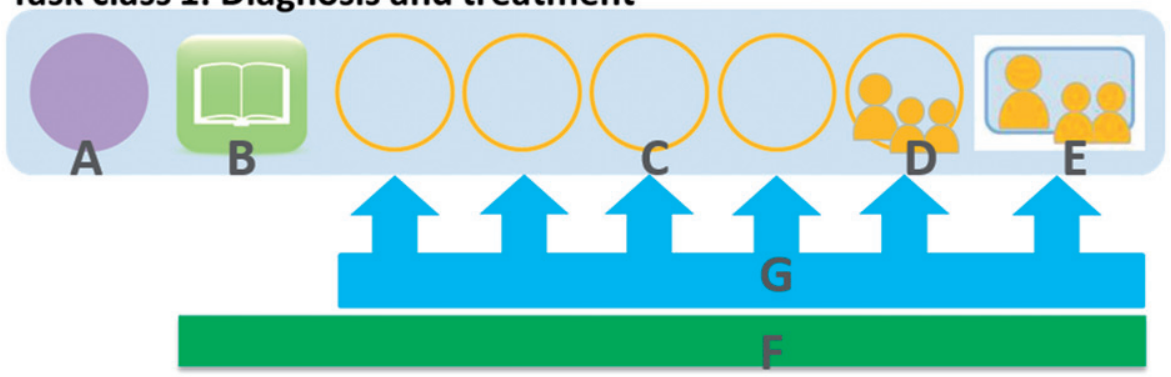

Figure 3. Content of task class 1: Diagnosis and Treatment (learning module "Patient with diabetes").

course chapters. This supportive information is available throughout all tasks. This is also visually presented by the lowest bar (see Figure 3, part F). In the next section, the design of the supportive information is described in more detail.

After a student has read the supportive information documents as part of the second task, several tasks are offered (presented by the large circles, see Figure 3, part C). For example, the second task class in the module "Patient with Diabetes" focused on management. The second task in this task class more specifically focused on the optimization and update of management and treatment for patients with diabetes. To complete this task, students had to answer 10 questions in different formats (multiple answer, sort, fill-in-the-blank, complete, etc.). Figure 4 presents an example of a question in drag-and-drop format.

All questions in this task had the same structure: a patient case is presented, or is presented in more detail (as compared to a previous question), or is presented with more elements to take into account (like previous treatments). Appendix A presents an overview of all possible types of tasks in the learning environment and is available as Supplemental Material at http://informahealthcare.com/journal/mte.

While the majority of tasks aim for individual completion, other tasks are group tasks or tasks that are completed or discussed during class hours. This is indicated by the circle with a people icon within (see Figure 3, part D, last circle). Examples of such group tasks are as follows: the online preparation of a patient case followed by a group discussion during class hours, the group discussion of a patient case on the discussion forums with the instructor providing feedback during class hours, a collaborative writing of a treatment plan, and so forth.

A last icon that is depicted in Figure 3 (part E) is the faceto-face classes. During these classes, instructors can provide feedback on students' learning outcomes of the learning module; they can provide additional information if any gaps in knowledge, skills or attitudes were identified during task completion in the computer-based learning environment (based on computer-based correction of tasks); and they can elaborate more on certain topics that were discussed in the learning module (based on forum posts and discussion threads). The face-to-face class icon also indicates when students are expected to complete the tasks: before, around or after the class is organized.

A last type of tasks pertains to training or workplacebased tasks. For example, one of the training tasks in the learning module "Care for the elderly" is the following: "During your internship you will meet older patients. Note the initials of one of those patients and discuss this patient with your training supervisor. How do you set up a long-term 


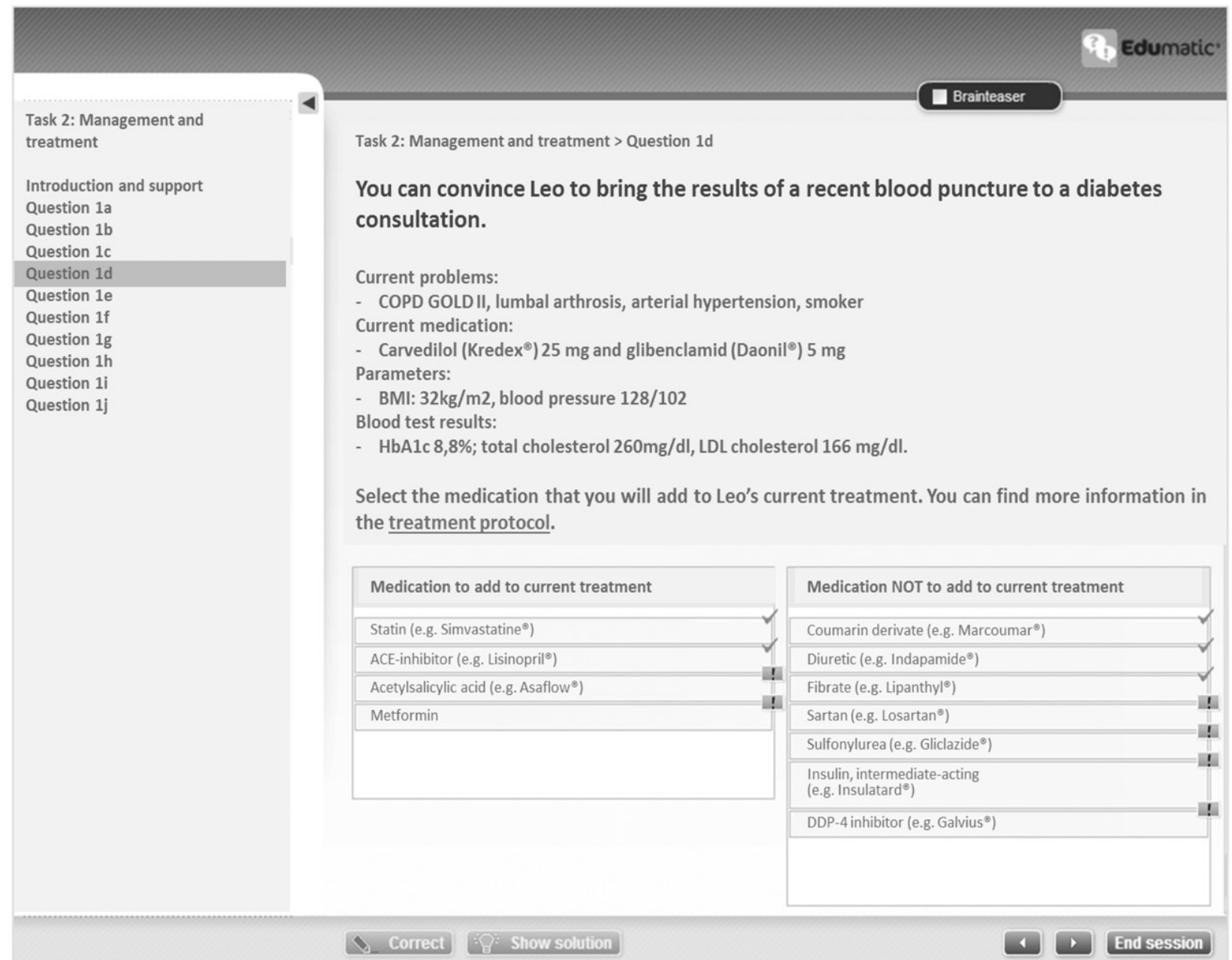

Figure 4. Example of drag-and-drop exercise with correct answer feedback.

healthcare plan for the elderly? What is possible for you to do in your own general practice? What are the points that need attention? Please bring your report with you to class 3 of 'Care for the elderly"'. Because of the increasing complexity of tasks within a task class, a student needs to integrate all knowledge and skills about elderly healthcare and should be able to take multiple roles as physician and more specifically, as a general practitioner (medical expert; communicator to and collaborator with patients, family, nurses, colleagues; health promoter towards patients and professional with respect to management and planning) to complete the training or workplace tasks. Moreover, the training tasks are accompanied with unsupported assessment (van Merriënboer \& van der Vleuten 2012). Unlike the (supported) assessment during task completion in the computer-based learning environment where all support materials were available and where the amount of support decreased gradually over tasks, students now have to seek information on a self-directed basis as they also should seek information in their future medical practice. This is in line with the principle of decreasing the amount of support and guidance for tasks within a task class. The last set of tasks has no built-in support hence providing minimal or no support to students. Questions such as: "What is possible for you to do in your own medical practice?" encourage students to engage in deliberate practice and to reflect on their own (future) performance. Moreover, students receive feedback from both the training supervisor (during internship) and the instructor (during class hours), again fostering deliberate practice. By explicitly considering the students' internship as the extension of their learning process, transfer between classroom learning and internship learning (and the other way around) is increased.

\section{Component 2: Supportive information}

Supportive information, traditionally called "the theory", helps learners with the problem solving and reasoning aspects of the learning tasks. Typically, supportive information is important for the fruitful completion of non-recurrent aspects of learning tasks, that is, those aspects that require problem solving, reasoning or conscious decision making even after the completion of the educational program. In order to develop the supportive information that needs to be incorporated in the learning environment, three steps can be taken. In Figure 3, supportive information is schematically shown by the lower bar and the booklet icon. 
Table 3. Relevant principles and auxiliary steps for the development of component 2: Supportive information.

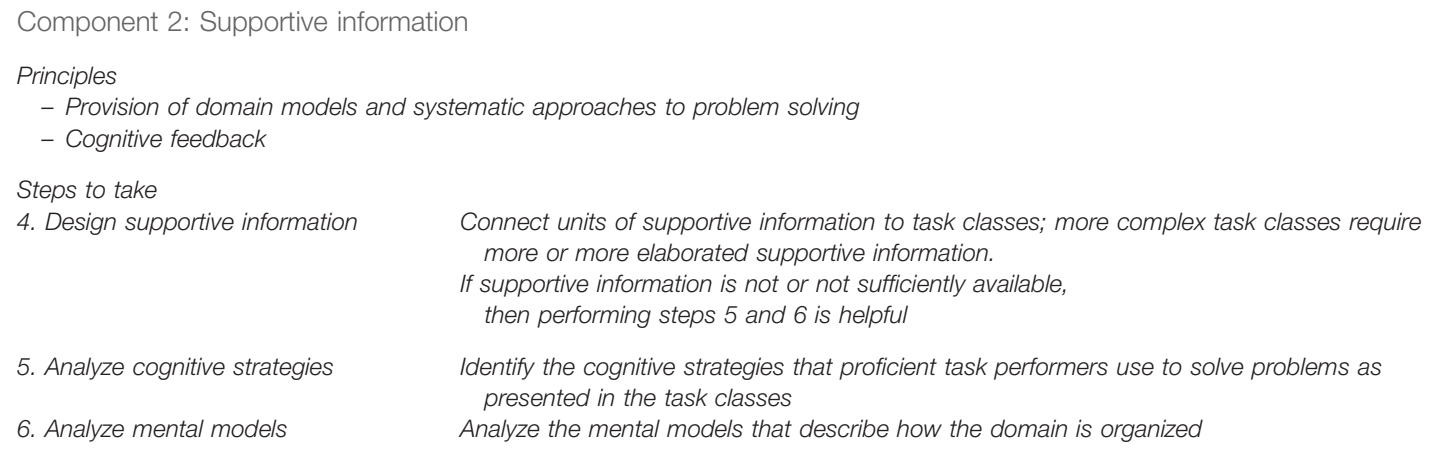

\section{Steps 4-6: Design supportive information}

The supportive information provides the learner with new information that is needed to complete the non-routine aspects of learning tasks. The provided supportive information is hence tailored to the content of each task class and can be accessed in accordance with the learners' needs (already existing and yet to be acquired knowledge). It helps learners to construct cognitive schema (e.g. illness scripts, treatment protocols, systematic approaches and rules-of-thumb for clinical reasoning or decision making), but it can also provide cognitive feedback, inviting the learners to critically compare and contrast their own schema with those of experts or peer students.

The cognitive schema, as reflected by the supportive information, come in two forms. First, there are the cognitive strategies (step 5), providing systematic approaches to problem solving in this domain, like heuristics and rules-of-thumb and second, there are the mental models (step 6) that reflect how the learning domain is organized and hence allow for reasoning within the learning domain. For example, treatment plans for patients with diabetes provide physicians with a systematic approach toward treatment and follow-up of patients with diabetes. Mental models, on the other hand, can be described as personal theories that are actively created and are informed by previous experiences with similar situations. Mental models can be extended with new experiences or they can be revised if one encounters a discrepancy between a real-life experience and the beliefs as represented in the mental model (Sandars 2009).

Given the relevance of this supportive information for the different tasks within a task class, this information is offered at the beginning of a task class and should stay available during the work in a task class. A new task class will also request (partly) different or more elaborated supportive information.

Next to the provision of mental models and cognitive strategies, supportive information also encompasses cognitive feedback. This type of feedback is provided on the quality of non-recurrent aspects of performance (van Merriënboer et al. 2002). Because non-recurrent aspects of performance cannot simply be rated as "correct" or "incorrect", but rather as "more or less effective", cognitive feedback stimulates learners to reflect on the quality of their approach to the problem-solving process. This can be done by debriefing sessions, peer or expert critiques and group discussions (van Merriënboer et al.
2002). As such, cognitive feedback is best offered after learners have completed a series of tasks or have finished a whole task class (van Merriënboer et al. 2002).

Summarizing, supportive information helps the learner to carry out the non-recurrent or non-routine aspects related to problem solving, reasoning and decision making while completing the learning tasks. Units of supportive information are defined at the level of a task class (not at the level of single tasks). Table 3 summarizes the steps to be undertaken to specify the supportive information. When existing instructional materials are of sufficient quality, then the design of supportive information can be limited to step 4 by reorganizing the materials according to the task classes. However, when new or additional support needs to be developed, steps 5 and 6 will assist in this process.

\section{Illustration}

Supportive information (Figure 3, part F) is offered in several ways. First, at the start of the task class, students are informed about the performance objectives that are set for the task class (i.e. what they will be able to do after completing the learning tasks), and performance standards (i.e. criteria, values, attitudes that describe acceptable performance). For example, for the task class focusing on the management of a patient with diabetes the performance objective is as follows: "In preparation for a consultation with a diabetic patient, the student is able to perform a focused search for evidence-based literature, to faultlessly draw relevant conclusions, to use these to draw a management plan that aims at a better quality of care for his diabetic patient and that is in line with the ruling healthcare policy". This performance objective entails several performance standards like criteria, values and attitudes. One criterion refers to the minimum requirements that a student must meet in terms of amongst others accuracy, time requirements and errors (e.g. faultlessly draw relevant conclusions and in preparation for a consultation with a diabetic patient). A value describes the rules, regulations or conventions by which a non-constituent skill should be performed (e.g. to perform a focused search for evidence-based literature and implement a management plan that is in line with the ruling healthcare policy). The attitude that is required for an acceptable management is a patient-centered attitude and patient-directed communication. 
Furthermore, during the first task (worked example) students get feedback on their answer and are provided with the expert's answer to the question and the reasoning process to come to the most appropriate or acceptable answer. In this way, students are encouraged to reflect on the cognitive strategies and mental models that are used by experts and they can strengthen their own models of how the domain is organized and strategies of how to systematically approach tasks in the domain.

After completing the worked example (first task), students are instructed to read a selection of supportive materials. Typically, these materials focus on the theory and comprise a lecture, a narrative presentation, course documents and research articles focusing on theoretical and practical insights that are relevant in the treatment of patients with diabetes. This information is divided into compulsory information (i.e. the student is strongly encouraged to read all documents) and optional information (i.e. the student can read the documents at a later time, while progressing through the tasks in the task class and learning module).

A last way by which supportive information is offered to students is by providing them cognitive feedback on task performance. This type of feedback comprises elaborated feedback on students' answers and solutions by providing the student with the correct answer and by presenting the problem solving approach to reach the (most) appropriate answer. As such, this feedback links to information that can be related to existing mental models and to a students' cognitive strategies for problem solving (like theoretical insights, exclusion and inclusion criteria) and eventually suggests students to consult or re-consult the supportive information. To encourage this consulting of supportive information, students are directly provided with links to the documents relevant for this task and task class. A specific form of cognitive feedback on task performance is provided by "reflection prompts". The use of such prompts can urge students to reflect on experts' or peers' performance or to self-reflect on their own performance (Paas \& van Gog 2009). From a practical point of view, reflection prompts can be given as side-tasks where students are encouraged to collaboratively discuss topics provided by the instructor or task solutions provided by peers. Based on this feedback from peers, students themselves are again prompted to reflect on their performance, encouraging the development of deliberate practice skills.

\section{Component 3: Procedural information}

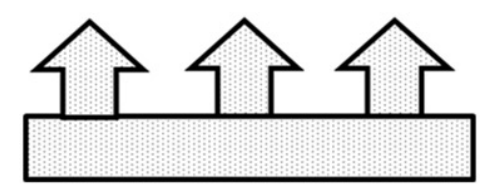

In contrast to supportive information that focuses on nonroutine aspects of tasks, procedural information or "justin-time information" provides information on how to perform recurrent aspects of learning tasks, that is, those aspects that need to be performed by the learner as routines after the educational program has been completed. The procedural information is schematically presented in Figure 3 by the rectangle with upward-pointing arrows.

The presentation of procedural information should facilitate schema automation and in order to do so, it should best be available during working on the task. This is information that learners need while performing a task, and hence it is best given exactly when they first need it to perform a task (i.e. precisely and just-in-time). This type of information is given step-by-step, since it constitutes the procedures and rules, facts and concepts needed to perform the routine; for example, it might be the support given while a student, for the first time, accesses a patient's electronic health record (e.g. "1/click 'name'; 2/provide the patient's full name including middle names" or " $1 /$ click 'diagnosis'; 2 /double click the right clinical diagnosis"). The information is available throughout the whole task and gradually disappears or fades away as the learner's skill increases. One way to offer procedural information is corrective feedback. When learners do not correctly apply the rules that describe effective performance, it is said that they make an error. Immediately after such a misapplication of a rule is detected, corrective feedback should be presented (van Merriënboer \& Kirschner 2013). Then, a learner can compile a rule that attaches the correct action to its critical conditions.

\section{Steps 7-9: Design procedural information}

As in the development of supportive information, if there are already useful instructional materials available (e.g. manuals, checklists, quick reference guides and job aids), then no further development is required, and the materials can be linked to the appropriate learning tasks. However, if new procedural information needs to be developed, then steps 8 and 9 can be helpful. Table 4 summarizes the steps related to the procedural information.

\section{Illustration}

Procedural information (Figure 3, part G) is offered at the level of individual tasks, focuses on how to perform routine aspects of learning tasks and is therefore best provided just-in-time. A preferable way to present this procedural information is stepby-step instruction. For example, in the Diabetes learning module, the first tasks concentrate on guiding the students stepwise through the routine steps of a consultation. Tasks focused on questions like "what is the reason for the visit?"; "what is the key question in the history taking?"; "what is the most likely diagnosis?"; "what is the most suitable treatment?" Doing so, students receive step-by-step procedural information for fruitful completion of the consultation. Later, tasks may then focus more on the non-routine aspects of consultation such as clinical reasoning strategies, dealing with additional information and integrating evidence-based guidelines into the treatment plan.

Procedural information can also be offered in the form of corrective feedback during or after task performance. Tasks can be split up in several exercises or items as to be able to immediately detect misapplications of rules that could lead to less effective or non-effective performance on tasks. Consequently, corrective feedback can be offered after every exercise or item students solved within a task. However, as 


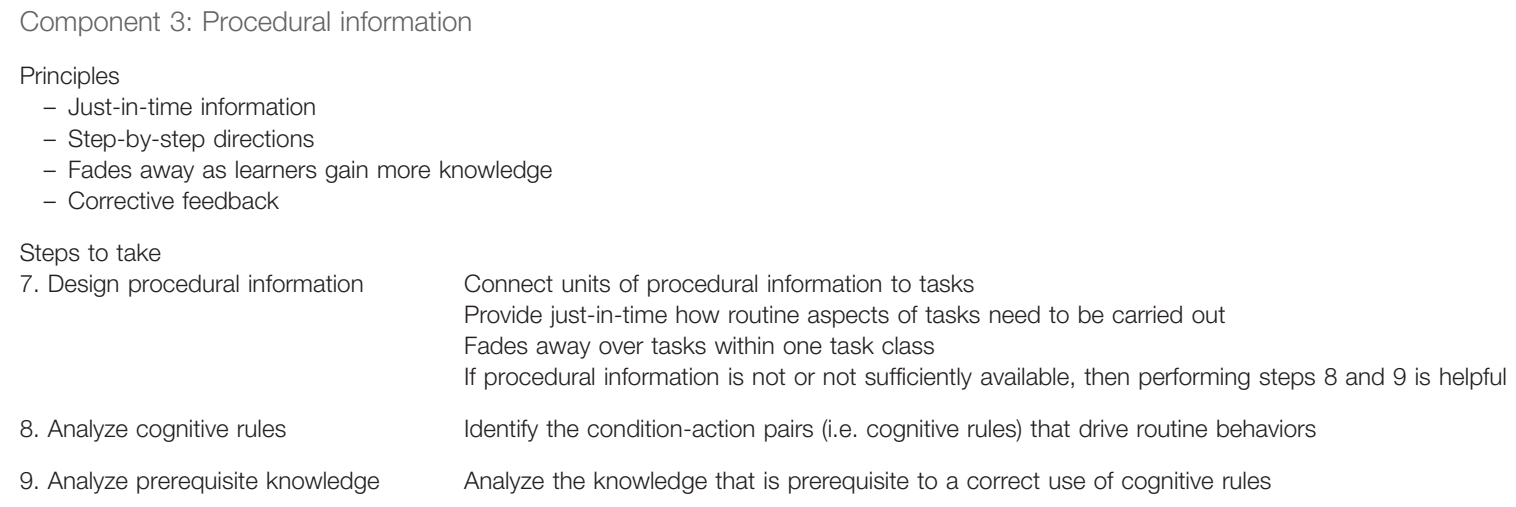

students' progress through the tasks in a task class, procedural information gradually disappears or fades away. This is done by providing less elaborated corrective feedback, by providing links to information instead of presenting the information, by providing summaries of protocols instead of complete protocols, and so forth.

\section{Component 4: Part-task practice}

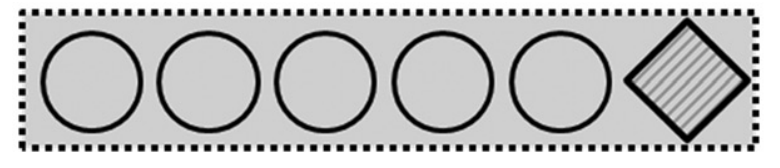

Part-task practice may be helpful when a very high level of automaticity is required for a particular recurrent aspect of the task. The aim is to strengthen schema automation, and hence it typically involves a lot of repetitive practice (see Table 5). Part task practice is not always part of the learning environment, but it may be necessary to include some additional part-task practice in a training program.

\section{Step 10: Design part-task practice}

Within medical education, part-task practice typically will focus on to-be-automatized parts of a consultation not only like clinical skills (measuring blood pressure, liver palpation and auscultation) and technical skills (e.g. venipuncture, suturing and CPR) but also practicing spot diagnoses. When designing a learning environment on the consultation with a child with fever, one may choose to offer part-task practice on the diagnosis of prototypical examples of childhood infectious diseases (spot diagnosis). This skill of performing a correct spot diagnosis needs to be highly automatized because it requires that a student is able to quickly recognize the relevant symptoms, to exclude irrelevant symptoms and to identify the next steps for completing the diagnostic reasoning process. An online quiz with photos and immediate feedback on every question would be a good option.

\section{Illustration}

Part-task practice, as applied in this learning environment, comprises several multiple-choice questions where students
Table 5. Relevant principles for the development of component 4: Part-task practice.

Component 4: Part-task practice

Principles

- Compilation and strengthening of rules

- Promotes automaticity of particular recurrent aspects

- Practice items with just-in-time information

are introduced to a young child showing prototypical presentations of childhood infectious diseases (spot diagnosis). The feedback on the questions focused on supportive information that elaborated on protocols for correctly diagnosing the disease of interest and for correctly excluding other diagnoses. Figure 5 provides an overview of a set of part-task practice exercises in the multiple-choice format.

\section{Implementation strategy and management plan}

Whilst guided by the 10 steps for developing the contentrelated aspects of the 4C/ID-based learning environment, as described in the previous sections, several other issues arise and need to be handled. Although there is accumulating evidence that the whole-task approach is effective and efficient (van Merriënboer \& Kester 2008; Merrill 2012), the development and implementation of whole-task models (like the 4C/ID model) is often inhibited, even restrained, by many practical, theoretical and technical issues. Therefore, it is advisable to have an implementation strategy and management plan. The change from traditional face-to-face education towards a blended learning environment starting from whole tasks implies big changes in educational practice and professionalism of teachers. Therefore, one could use a model for leading change, presented by Kotter (1995) and applied in medical education by Steinert et al. (2007). Kotter (1995) presented eight frequently made errors in the process of change and suggested an equal number of actions in order to increase the chance for successful change. In Table 6, the actions, as described by Kotter (1995), are listed together with additional steps to be taken in the change cycle toward blended, whole-task learning in medical education. This is a cyclic process that might have multiple iterations in order to 


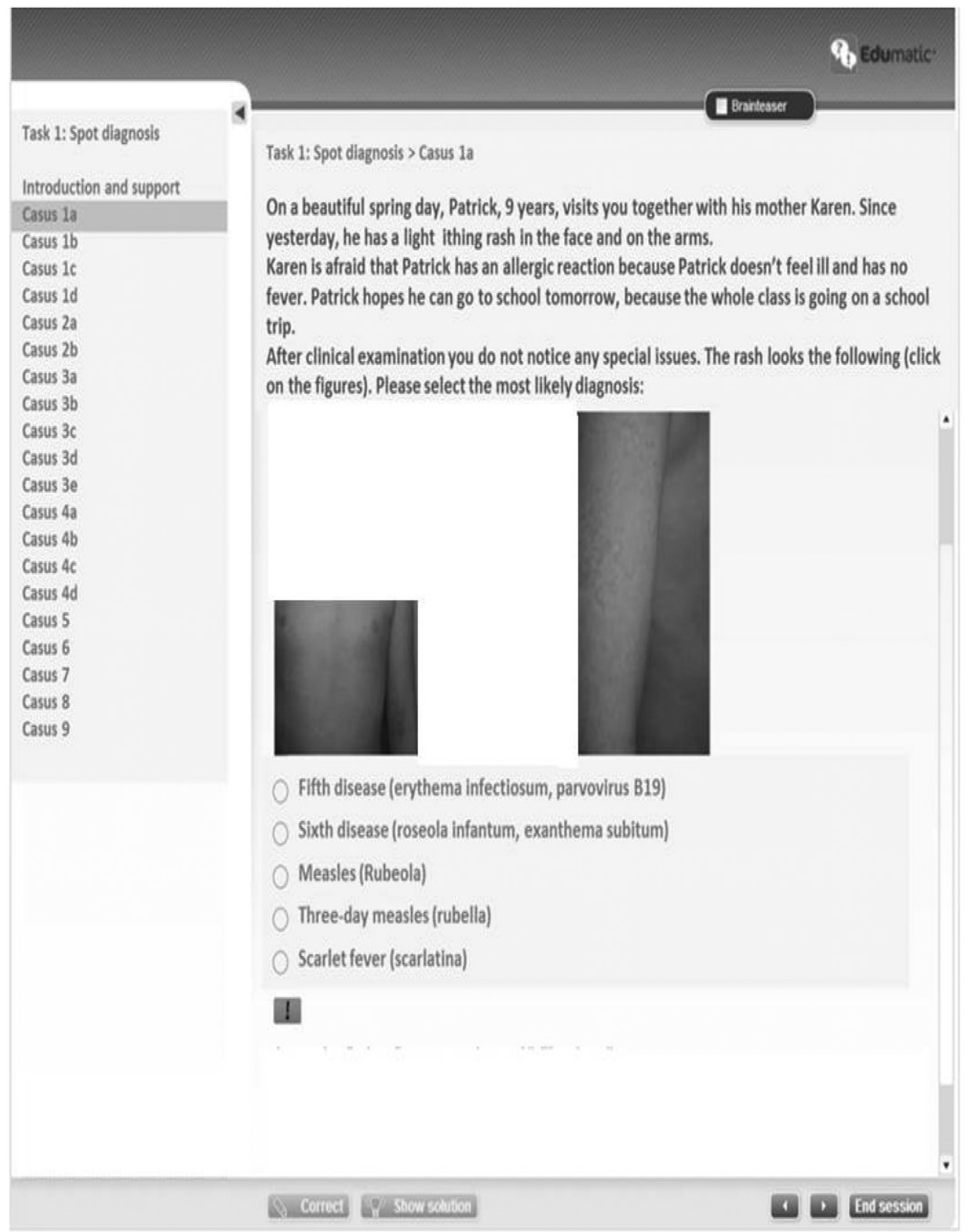

Figure 5. Example of part-task practice: multiple-choice exercise with correct answer feedback.

develop and optimize an evidence-based blended learning environment for whole-task learning.

\section{Action 1: Establish a sense of urgency}

Define what practices of (medical) education can and should be improved. Define short-term and long-term improvements

In our case, there was the observation that there was not sufficient integration of theory and practice and that there was also a lack of transfer from what had been learned during classes to what was seen during internship (and the other way around). However, as medical education increasingly stresses the integrated acquisition of multiple competences, there was a discrepancy between the way instruction was offered to students and the goals of medical education. This led to a raised awareness for adjusting the educational practice toward a higher standard.

\section{Action 2: Form a powerful guiding coalition}

Define the stakeholders: end-users of the learning environment, educational specialists familiar with (blended) learning environments, content developers, teachers and management

In line with the tips that Dolmans et al. (2013) provide, it is of utmost importance in this process to (1) form multidisciplinary teams comprising several medical disciplines (like communication experts, diabetes experts and medical imaging experts) and instructional designers, and (2) prepare and motivate team 


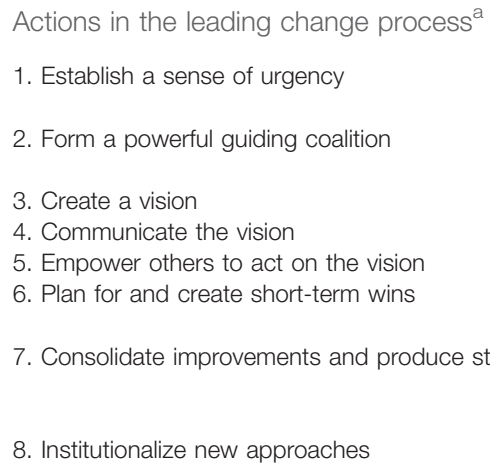

\section{Actions in the educational change process}

Identify what practices of (medical) education can and should be improved. Define short-term and long-term improvements.

Identify the stakeholders: End-users of the learning environment, developers, teachers and management

Apply evidence-based principles

Communicate the instructional approach with all stakeholders

Teach the teachers

a. Identify high quality learning materials

b. Prototype testing with small user groups

Work future-oriented

b. Evaluate with all end-users

c. Document

Disseminate and discuss

${ }^{\mathrm{a} B a s e d}$ on Kotter (1995) and Steinert et al. (2007).

members to fulfill different roles (medical expert, content creator, content reviser, supervisor for training tasks, etc.) and to reflect on their methods of instruction. The first is crucial for the development of balanced, whole-tasks that integrate different aspects of authentic tasks; the latter is of added value when it comes to the development, successful implementation and follow-up of the learning environment. For example, once decided to use an instructional design model to support the re/development of a learning environment, the stakeholders need to assess every element of the model to its asset value. To illustrate this, in the General Practice 4C/ID model, the component of part-task practice was left out in some learning modules because high levels of automaticity for selected task aspects were not part of the objectives of that specific learning module. A powerful guiding coalition forms a counterbalance for instructional designers that consider all elements in the model as assets ("it is a validated model, after all"), and for teachers and content developers that consider only those elements that are easy and practical to implement.

\section{Action 3: Create a vision}

\section{Apply evidence-based principles}

Medical education research can genuinely evolve by investigating and applying empirically sound principles from instructional design research. Cognitive psychological research, for example, can be of great value for medical education (Schuwirth 2010). An illustration of this value is given by van Merriënboer \& Sweller (2010) discussing how cognitive load theory can be applied in health professional education. One principle that is highly relevant in this context is the expertise reversal effect indicating that principles that work well for novice learners are not always beneficial, and can even be detrimental, for more advanced learners. For example, a worked example that is offered at the beginning of a task class becomes redundant for more knowledgeable learners. Worked examples are initially introduced to reduce a (novice) learner's cognitive load by providing a full solution that needs to be studied carefully. Instead of investing effort in trying to generate a solution, learners can invest all effort to studying the expert solution and elaborating on the example. Irrespective of what instructional design principles are used to define the vision towards educational innovation, they will largely define the choices to be made in the design, development and implementation of the innovation. Hence, explaining and communicating this vision and its underlying principles will support all stakeholders to genuinely contribute in the process of educational innovation.

\section{Action 4: Communicate the vision}

\section{Discuss the instructional approach with all stakeholders}

This action is intended to make the vision, and its underlying principles, clear toward all stakeholders. In an initial meeting, the instructional design method (in this study, the 4C/ID model) can be introduced to and discussed with the instructors and content developers involved in the educational change. One can start from the original 4C/ID model but may need to make modifications based on the feedback of the stakeholders that is given during the initial meeting. In our specific case, teachers and students indicated that the structure and wording of the components in the 4C/ID model was not entirely clear to them. Consequently, the visual presentation of the model was made clearer with icons that were specifically developed for this application of the 4C/ID model in medical education. By consequently using these icons to label tasks, supportive and procedural information, worked examples and so forth, students, instructors as well as content developers became familiar with the structure of the learning environment and could easily find their way and navigate through tasks and task classes. Furthermore, by indicating the total set of tasks and informing students of their progress through the task classes, students could easily manage the completion of tasks and tasks classes. Adding icons to make the approach more clear was a consequence of discussing the vision with the stakeholders at an early stage.

\section{Action 5: Empower others to act on the vision}

\section{Teach the teachers}

Roadmaps or templates guide the content developers stepwise through the development process and are built around the elements that are required per task class, providing additional information per element. To introduce the roadmap, one could organize a hands-on session for teachers and content 
developers wherein the instructional approach is illustrated with practical examples. The roadmap as used for the development of the General Practice 4C/ID model is provided in Appendix B, available as Supplemental Material at http:// informahealthcare.com/journal/mte.

For example, when a content developer starts a new set of tasks, the first question in the roadmap is to define the performance objectives and achievements of the set of tasks, or, in other words: what real-life tasks should medical students be able to perform correctly in order to achieve what the program aims for (steps 1-3: Design learning tasks). This assists the developers in developing a varied set of tasks that jointly involve all performance objectives defined for that task class. The learning tasks need to be specified before the objectives, standards and assessment instruments in order to avoid that learning objectives are determined early in the development process with the risk of being abandoned or revised later on in the learning process to correspond more closely to the content that has finally been developed (van Merriënboer \& Kirschner 2013). Subsequently, the roadmap lists possible examples of supportive information (steps 4-6: design supportive information), after which content developers can indicate what documents, links or resources they want to be offered to students. On the task level, a list is provided with exercise types and examples as to inform the content developers of the possibilities in task development (step 1: design learning tasks). For all tasks, developers are requested to provide the reasoning process that results in the most optimal or correct answers (steps 4-6: design supportive information) and to list the general (step 4: design supportive information, cognitive feedback) and fault-specific (step 7: design procedural information, corrective feedback) feedback that should be offered to students. This structured way of content development allows both instructional designers and content developers to develop the learning environment efficiently.

\section{Action 6: Plan for and create short-term wins}

\section{Plan for short-term wins: use or reuse learning materials of high quality}

In the development of a (computer-based) learning environment for the acquisition of medical knowledge, skills and attitudes; all available learning content should be viewed at from three angles:

(1) Are the existing learning materials of sufficient high quality to foster the integrated development of knowledge, skills and attitudes, taking into account the different roles a physician should be able to take in his/her practice?

(2) Is there sufficient variability in task type and interactivity within the learning modules? To assure high variability and a range of interactivity, existing learning materials can be categorized into the way they are presented (see roadmap in Appendix B, available as Supplemental Material at http://informahealthcare.com/journal/mte) as to identify the degree of variability and interactivity that is already present. To foster variability and different forms of interactivity, one could create an overview of several types of learning tasks (see Appendix A, available as Supplemental Material at http://informahealthcare.com/ journal/mte), and indicate for all types in what context the task can be offered (training task in internship, task in course class, online text questions, online video), what interactivity was possible (student-student; student-environment; student-instructor; student-class) and how student performance could be evaluated (step 2: develop assessment instruments).

(3) Are the (existing) learning materials suitable enough to be offered via computer-based instruction? This question stems from the notion that the effectiveness and efficiency as obtained by the use of paper-and-pencil materials does not necessarily hold when this content is offered in an online content management system as the infrastructure for the learning environment. Not only is this due to the nature of the learning materials but also to the technical characteristics and restrictions of the environment in which the content is offered.

\section{Create short-term wins: prototype testing with end-users}

The contribution of students and teachers as future end-users should not be underestimated when it comes to receiving feedback on the environment's strengths and weaknesses (Dolmans et al. 2013). A major pitfall in the design, development and testing phases is not making use of future users' insights. In this case, both instructors and students were considered as end-users of the learning environment and already in the conceptual design phase they were involved to critically reflect on the elements in the learning environment. In line with the suggestion by Dolmans et al. (2013) to explain the ideas behind the innovative whole-task approach, user groups were organized in which the principles and structure of the learning environment were presented and discussed. The discussions in the user groups provided valuable information to further refine the learning environment. By continuously involving the users in the process of design and development, at first sight, critical users may become the best advocates of the new approach. Moreover, students become familiar with the instructional methods and the expected learning approaches.

\section{Action 7: Consolidate improvements and produce still more change}

\section{Work future-oriented}

With respect to future development and sustainability of the learning environment, learning materials can be provided with metadata. Metadata can label learning materials with values for subject, education level, performance objectives, intended users, number of roles to integrate, and so forth. The added value of metadata is that they allow for searching repositories of learning materials in order to find content that meets the required criteria (Ellaway \& Masters 2008), but they also foster reuse of learning materials in other environments. In this Guide, we have proposed a first attempt to a metadata overview by describing the criteria and their parameters by which learning materials are categorized. 


\section{Evaluate with all end-users}

After students complete all tasks in the learning environment (including internship tasks), both qualitative and quantitative evaluations can be performed. Three end-user groups need to take part in the evaluations: students as they can be considered as the primary end-users of the learning environment; teachers as they have used the learning environment as a tool in their educational practice; and developers or educational specialists as they likely have encountered technical and practical issues that need to be dealt with in a future cycle of innovation. Evaluations may focus on the quality of the content as well as on the user-friendliness and functionality of the learning environment. For example, rating scales that indicate the satisfaction of students with the overall structure of the learning environment, the quality of the tasks and support materials, the practical organization of classroom instruction and computer-based instruction, interface design, the interaction with teachers and other students, etc. provide input for further improvement of the learning environment. Openended questions on what end-users would improve or change can also form the basis for future changes in educational practice.

\section{Document}

In the progressive process of developing and implementing a learning environment, documenting what has been developed, what steps have been taken, what issues have been dealt with and how may seem like a rather disturbing task that interrupts the flow wherein all team members are. However, documenting offers great advantages as it is one of the backbones of the next successful educational innovation. There are a number of reasons why one could decide to spend enough time on documenting: it keeps all team members on track, it keeps the stakeholders informed; it provides a back-up for the team members; it provides clarity and traceability; it provides a starting point for dissemination and with good documentation, the time needed to support and train teachers is reduced. When deciding what to document the following elements should be included: risks and technical issues that were encountered and how they were dealt with; all re-usable materials like icons, videos, pictures; identification of educational materials on websites; reports on development and implementation; reports on testing by small user groups; suggestions made by stakeholders and a separate document where do's and don'ts are listed for future end-users of the learning environment.

\section{Action 8: Institutionalize new approaches}

\section{Disseminate and discuss}

As a last step in the change process, Steinert et al. (2007) suggested to anchor the new approaches in the culture of the institution. For this anchoring, dissemination is needed in order to create a widespread support for endorsement of the new approach in the medical curriculum. By disseminating the process of development and implementation, one gets feedback from peer researchers, peer teachers and peer designers, which again provides input for optimization of the current and future learning environments. Moreover, dissemination allows to discuss what successful elements in the change process can be transferred to other parts of the medical curriculum as to further stimulate innovation in medical education.

\section{Conclusion}

In this guide, the reader was introduced to the 4C/ID model, an instructional design model that supports complex learning. The model was illustrated with an example of a blended learning environment in a general practice curriculum. The learning environment, as proposed in this guide, is in accordance with the whole-task approach, where a learning domain (i.e. general practice) is considered as a coherent, integrated whole and where teaching and instruction start with relatively simple, but authentic tasks and gradually proceed to more complex tasks.

As van Merriënboer \& Kirschner (2013) describe, the 4C/ID model and its accompanying 10 steps to complex learning can form the basis for designing educational tasks with established and well-known educational approaches such as problembased learning (Norman \& Schmidt 2000) and constructivist learning (Jonassen 1999). The 4C/ID's four main constituents can be incorporated throughout all instructional design models that promote effective learning.

The 10 steps to complex learning (as described by van Merriënboer \& Kirschner 2013) provide a good starting point for the design of powerful learning environments that promote complex learning. The steps and underlying theoretical assumptions can be considered as guidelines and markers in developing or optimizing a learning environment as described in this guide. Depending on the already available knowledge about instructional design in the institution, the existing good practices and practical issues to deal with (like time efforts and available support for teachers) the 4C/ID model can be implemented in several gradations, varying from the enrichment of existing complex learning tasks with part-task practice where deemed relevant, or providing worked examples at the beginning of a set of learning tasks, to reforming whole courses or even the curriculum of medical education based on the $4 \mathrm{C} / \mathrm{ID}$ principles. The $4 \mathrm{C} / \mathrm{ID}$ model is based on a broad range of evidence-based principles from research on instructional design, cognitive psychology and information processing theories, hence implementing parts of the model in accordance with the steps as described by van Merriënboer \& Kirschner (2013) and in this Guide, is likely to improve the instructional design.

Parallel with the decision to start implementing (parts of) the 4C/ID model, practical and technical issues should also be taken into account. In this Guide, Kotter's (1995) actions to prevent frequently made errors in the process of change are listed together with the steps to increase the successful implementation of a blended, whole-task based learning environment for medical education.

Concluding, two major tools were provided in this guide. On the one hand, based on the 4C/ID model, there are 10 steps for the development of whole-tasks that can be offered in a blended learning environment for medical education. On the other hand, the actions to be taken in order to ensure 
successful (long-term) implementation were discussed. With these tools, medical teachers and instructional designers in medical education are well equipped to further introduce the whole-task approach in medical education and to deal with practical, theoretical and technical issues. In addition, new research lines can be developed wherein the effectiveness of the whole-task approach is sketched in a variety of learning situations, for a variety of medical students, hereby strengthening the validity of the whole-task approach.

\section{Notes on contributors}

MIEKE VANDEWAETERE, PhD, is a member of the Faculty of Medicine at the University of Leuven at Kulak and has also worked as a member of the Center for Instructional Psychology and Technology. As a cognitive psychologist and data-analyst, her research interests focus on the design, development and evaluation of computer-based and game-based learning environments for complex learning. For the evaluation of learning environments, she uses research methods from user-centered design and educational data mining methods as well. More recently, her research focus moved toward innovations in medical education and more specifically the use of simulations in undergraduate medical education.

DOMINIQUE MANHAEVE, RN, Master's Medical and Social Sciences, after an initial career as project manager within the field of clinical research, Dominique joined the Academic Centre for General Practice in 2011 as a scientific associate for the "Levensecht Leren"-project. The project implements the 4C/ID-model in the curriculum of the medical school. She is also a scientific associate for the Elderly Care Research unit of the KHLim (Limburg Catholic University College) where she coordinates research projects involving experiential learning programs for nursing and care staff.

BERT AERTGEERTS, MD, PhD, is a Full Professor of General Practice and Director of the Academic Center for General Practice at the University of Leuven where he is Head of the General Practice curriculum. He is also the coordinator of scientific education at the Faculty of Medicine (KU Leuven). As Chairman of the Center for Evidence-Based Medicine (CEBAM, Belgian branch of the Cochrane Collaboration), his interests are mainly in evidencebased medicine and guidelines.

GERALDINE CLAREBOUT, PhD, is the Head of the Educational Support Office of the Faculty of Medicine of the University of Leuven. As an educational scientist she performs research in the domain of educational technology and more specifically instructional design. Her interest lies in students' use of support devices in electronic learning environments and how this use can be optimized.

JEROEN J. G. VAN MERRIËNBOER, PhD, is a Full Professor of Learning and Instruction and Research Director of the School of Health Professions Education (SHE) at Maastricht University, The Netherlands. He was trained as an experimental psychologist at the VU University Amsterdam and received his $\mathrm{PhD}$ in Educational Sciences from the University of Twente (1990). He has been working at the University of Twente, the Open University of the Netherlands and Maastricht University, and he worked as a visiting professor at the University of Barcelona in Spain and the University of New South Wales in Australia. Most of his research is based on the 4C/ID model and cognitive load theory, nowadays mainly in the health-sciences domain.

ANN ROEX, MD, PhD, is an Assistant professor of General Practice at the University of Leuven. She received her PhD in Medical Sciences, focusing her study on medical students' epistemological beliefs. Her current scientific interest lies in the fields of innovations in medical education, more specifically the design of learning environments. She works as a general practitioner in Brussels.

Declaration of interest: The authors report no conflicts of interest. The authors alone are responsible for the content and writing of the article.

\section{References}

Davis MH. 2003. Outcome-based education. J Vet Med Educ 30(3):258-263. Dolmans DHJM, Wolfhagen IHAP, van Merriënboer JJG. 2013. Twelve tips for implementing whole-task curricula: How to make it work. Med Teach 35(10):801-805.

Ellaway R, Masters K. 2008. AMEE Guide 32: e-Learning in medical education Part 1: Learning, teaching and assessment. Med Teach 30(5):455-473.

Ericsson KA. 2004. Deliberate practice and the acquisition and maintenance of expert performance in medicine and related domains. Acad Med 79: S70-S81.

Fastré GMJ, van der Klink MR, van Merriënboer JJG. 2010. The effects of performance-based assessment criteria on student performance and self-assessment skills. Adv Health Sci Educ 15:517-532.

Fernandez N, Dory V, Ste-Marie LG, Chaput M, Charlin B, Boucher A. 2012. Varying conceptions of competence: An analysis of how health sciences educators define competence. Med Educ 46(4):357-365.

Frank JR. 2005. The CanMEDS 2005 physician competency framework. Better standards. Better physicians. Better care. Ottawa: The Royal College of Physicians and Surgeons of Canada.

Frank JR, Danoff D. 2007. The CanMEDS initiative: Implementing an outcomes-based framework of physician competencies. Med Teach 29(7):642-647.

Gerards-Last D, Geraets J. 2011. Klinisch redeneren in het fysiotherapie onderwijs. Tijdschrift voor Medisch Onderwijs 30(5):226-236.

Gibbs T, Durning S, van der Vleuten C. 2011. Theories in medical education: Towards creating a union between educational practice and research traditions. Med Teach 33(3):183-187.

Gulikers JTM, Kester L, Kirschner PA, Bastiaens ThJ. 2008. The influence of practical experience on perceptions, study approach and learning outcomes in authentic assessment. Learn Instruct 18(2):172-186.

Hoogveld B, Janssen-Noordman A, van Merriënboer J. 2011. Innovatief onderwijs in de praktijk, toepassingen van het 4C/ID-model. Groningen/Houten: Noordhoff Uitgevers.

Jonassen DH. 1999. Designing constructivist learning environments. In: Reigeluth CM, editor. Instructional design theories and models: A new paradigm of instructional theory (Vol. 2). Mahwah, NJ: Lawrence Erlbaum Associates. pp. 215-239.

Kotter JP. 1995. Leading change: Why transformation efforts fail. Harvard Business Rev 73(2): 59-67.

Mayer RE. 2010. Applying the science of learning to medical education. Med Educ 44(6):543-549.

Merrill MD. 2002. First principles of instruction. Educ Technol Res Devel 50(3):43-59.

Merrill MD. 2012. First principles of instruction: Identifying and designing effective, efficient, and engaging instruction. Hoboken, NJ: Pfeiffer (John Wiley \& Sons).

Norman GR. 2009. Teaching basic science to optimize transfer. Med Teach 31(9):807-811.

Norman GR, Schmidt HG. 2000. Effectiveness of problem-based learning: Theory, practice and paper darts. Med Educ 34:721-728.

Paas F, van Gog T. 2009. Principles for designing effective and efficient training for complex skills. In: Durso F, editor. Reviews of human factors and ergonomics (Vol 5). Santa Monica, CA: Human Factors. pp 166-194.

Paas F, van Merriënboer JJG. 1994. Variability of worked examples and transfer of geometrical problem-solving skills: A cognitive load approach. J Educ Psychol 86:122-133.

Sandars J. 2009. The use of reflection in medical education: AMEE Guide no. 44. Med Teach 31:685-695.

Schuwirth L. 2010. Medical education and other disciplines. Med Educ 44(1):13-14

Steinert Y, Cruess RL, Cruess SR, Boudrau JD, Fuks A. 2007. Faculty development as an instrument of change: A case study on teaching professionalism. Acad Med 82(11):1057-1064.

Swing SR. 2007. The ACGME outcome project: Retrospective and prospective. Med Teach 29(7):648-654.

van Herwaarden CLA, Laan RFJM, Leunissen RRM. 2009. Raamplan Artsopleiding. Nederlandse Federatie van Universitair Medische Centra. Available from www.nfu.nl. 
van Merriënboer JJG. 1997. Training complex cognitive skills: A fourcomponent instructional design model for technical training. Englewood Cliffs, NJ: Educational Technology Publications.

van Merriënboer JJG, Kester L. 2008. Whole-task models in education. In: Spector JM, Merrill MD, van Merriënboer JJG, Driscoll MP, editors. Handbook of research on educational communications and technology. 3rd ed. Mahwah, NJ: Erlbaum/Routledge. pp 441-456.

van Merriënboer JJG, Kirschner PA. 2007. Ten steps to complex learning. Mahwah, NJ: Erlbaum.

van Merriënboer JJG, Kirschner PA. 2013. Ten steps to complex learning. 2nd Rev. ed. New York: Routledge.

van Merriënboer JJG, Sweller J. 2010. Cognitive load theory in health professional education: Design principles and strategies. Med Educ 44: $85-93$. van Merriënboer JJG, van der Vleuten CPM. 2012. Technology-based assessment in the integrated curriculum. In: Mayrath MC, Clarke-Miruda J, Robinson DH, Schraw G, editors. Technology-based assessments for 21st century skills. Charlotte, NC: Information Age Publishing. pp 345-370.

van Merriënboer JJG, Clark RE, de Croock MBM. 2002. Blueprints for complex learning: The 4C/ID-model. Educ Technol Res Dev 50(2):39-64.

Vandercruysse S, Vandewaetere M, Cornillie F, Clarebout G. 2013. Competition and students' perceptions in a game-based learning environment. Educ Technol Res Dev 61(6):927-950.

Yardley S, Hookey C, Lefroy J. 2013. Designing whole-task learning opportunities for integrated end-of-life care: A practitioner-derived enquiry. Educ Prim Care 24:436-443.

Supplementary material available online 